\title{
On-Line LC/UV/MS Analysis of Flavonols in the Three Apple Varieties Most Widely Cultivated in Brazil
}

\author{
Luciana A. Tiberti, ${ }^{a}$ Janete H. Yariwake, ${ }^{* a}$ Karine Ndjoko ${ }^{b}$ and Kurt Hostettmann ${ }^{b}$ \\ ${ }^{a}$ Universidade de São Paulo, Instituto de Química de São Carlos, CP 780, 13560-970 São Carlos-SP, Brazil \\ ${ }^{b}$ Laboratoire de Pharmacognosie et Phytochimie, École de Pharmacie Genève-Lausanne, Université de Genève, \\ Quai Ernest Ansermet 30, 1211 Genève 4, Genève, Switzerland
}

\begin{abstract}
Este trabalho apresenta a primeira investigação sobre a estrutura química dos flavonóis presentes em cascas das três variedades de maçãs mais cultivadas no Brasil: Gala, Golden e Fuji. As análises foram feitas por CL/UV/EM (cromatografia líquida de alta eficiência com detector UV com arranjo de diodos acoplada à espectrometria de massas), usando adição póscoluna de reagentes de deslocamento de UV e também espectrometria de massas de múltiplos estágios $\left(\mathrm{EM}^{\mathrm{n}}\right)$ com ionização "electrospray" no modo negativo. A identificação "on-line" com base nos dados de CL/UV/EM demonstrou a presença de rutina, hiperosídeo, isoquercitrina, quercitrina e outros três derivados de quercetina-3-O-pentosídeo. As análises por CL/UV/EM também demonstraram que as três variedades de maçã têm perfis cromatográficos semelhantes.
\end{abstract}

This work describes the first detailed investigation into the chemical structures of flavonols present in the three apple varieties most commonly cultivated in Brazil: Gala, Golden and Fuji. The analyses were carried out by LC/UV/MS (high-performance liquid chromatography coupled to diode array UV detection and mass spectrometry), using post-column addition of UV shift reagents, as well as multiple stage mass spectrometry $\left(\mathrm{MS}^{\mathrm{n}}\right)$ with electrospray ionization in the negative ion mode. Rutin, hyperoside, isoquercitrin, quercitrin, quercetin and three other quercetin-3-pentoside derivatives were identified through the characterization of on-line-based LC/UV/MS data. LC/UV/MS analysis also revealed that the three apple cultivars have similar chromatographic profiles.

Keywords: apple, flavonols, LC/UV/MS, UV shift reagents

\section{Introduction}

Apple (Malus domestica Borkh., Rosaceae) cultivation stands out as an important and rapidly growing market segment in Brazil. While a few traditional apple varieties have been locally grown, such as Rainha, Soberana and Brazil varieties, other varieties such as Gala, Golden and Fuji have proved superior in terms of growth and productivity, particularly in Brazil's southern and central regions. ${ }^{1,2}$

Previous papers have reported on the chemical composition of apple varieties from the USA and from Europe, identifying the main components as esters of caffeic and coumaric acids, procyanidines and flavonols (quercetin glycosylated derivatives). ${ }^{3-10}$ In recent years, an increasing number of publications have reported the chemistry of flavonols, especially in view of their biological (antibacterial,

*e-mail: janete@iqsc.usp.br antiviral, anti-inflammatory, anti-allergic, anti-trombotic, vasodilatory, anti-mutagenic and neoplastic) properties and their ability to protect against or inhibit the development of cancer when consumed on a regular basis. ${ }^{11}$ Notwithstanding the data available from apple samples cultivated in the Northern hemisphere, it must be pointed out that the production of flavonols may vary in response to different environmental conditions. ${ }^{11}$ Therefore, the possibility of differences in the chemical composition of flavonols from samples cultivated in the Southern hemisphere cannot be excluded. Furthermore, the composition of flavonols in Brazilian apples has still only been partially investigated. Arabbi et al. ${ }^{12}$ quantified the flavonol content in Gala, Golden, and Fuji samples cultivated in Brazil, using aglycone quercetin as a standard, but did not elucidate the structure of these flavonols.

Our research groups have been working on the analysis of flavonoids from Brazilian food plants, ${ }^{13,14}$ emphasizing 
the use of on-line LC techniques as a tool for the chemical profiling of plant extracts. The hyphenation (coupling) of high-performance liquid chromatography with UV photodiode array detection (LC/UV) and liquid chromatography with mass spectrometry (LC/MS) provide spectrometric information comparable to those recorded for pure constituents. The molar mass as well as structural information can be obtained by LC/MS/MS or by in-source collision-induced (CID) fragmentation. The application of LC/MS and other LC-hyphenated techniques for the on-line structural investigation of plant compounds was reviewed. ${ }^{15}$

In the case of phenolic compounds such as flavonoids and xanthones, on-line UV spectra provide useful information (type of chromophore or pattern of substitution) complementary to those obtained with LC/MS. An important tool is the on-line addition of reagents that induce shifts in the UV absorption maxima $\left(\lambda_{\max }\right)$. LC/UV analysis with post-column addition of UV shift reagents provides useful information about the oxidation pattern, the position of free phenolic and methoxyl groups, and the position of the linkage of sugar moieties ( $O$ - or $C$-glycosylation).

In this paper, we report on a study of flavonols from the three apple varieties most commonly cultivated in Brazil (Gala, Golden and Fuji) by LC/UV and tandem mass spectrometry $\left(\mathrm{LC} / \mathrm{MS}^{\mathrm{n}}\right)$, using electrospray ionization $(\mathrm{ESI})^{16}$ in the negative ion mode. To the best of our knowledge, this is the first report on the characterization and identity of flavonols from samples of these apple varieties cultivated in Brazil using hyphenated techniques.

\section{Experimental}

\section{Plant material}

Samples of Gala, Golden, and Fuji apple varieties were kindly provided by the Fischer-Fraiburgo Group (Fraiburgo, Santa Catarina, Brazil). The cultivars were grown in the state of Santa Catarina, Brazil. The Gala, Golden, and Fuji samples were harvested within 25 kilometers from each other in February, March, and April, respectively, and were kept in conventional cold chambers $\left(-20{ }^{\circ} \mathrm{C}\right)$ in a controlled atmosphere. The apples were peeled manually (1-2 mm thickness) to separate the peels from the pulp. The peels were then dried at $40^{\circ} \mathrm{C}$, grounded into a powder and sieved, and only particles between 1.0 and $2.0 \mathrm{~mm}$ were used.

\section{Chemicals}

All chemicals and solvents were analytical or HPLC grade. The standards of rutin, hyperoside, isoquercetin, quercetin, and quercetrin were kindly provided by the
Institute of Pharmacognosie and Phytochimie, University of Lausanne, Switzerland. All standards were dissolved in methanol for HPLC analysis.

\section{Extraction of flavonols}

Samples of apple peels (1.0 g) were extracted under magnetic stirring with $10 \mathrm{~mL}$ of a methanol:water mixture (1:1) for 30 minutes at $50{ }^{\circ} \mathrm{C}$. The solid residue was filtered out and the extracts stored at $-20{ }^{\circ} \mathrm{C}$ before chromatographic analysis.

\section{LC/UV/MS analysis}

On-line LC/UV/MS analysis were performed on a HPLC system with UV photodiode array detector (PAD) coupled to a mass spectrometer. The experimental setup was previously described and discussed ${ }^{17}$ (see also Supplementary Information). A HP-1100 system equipped with binary pumps, an inline degasser, an autosampler, and a PAD detector (Hewllett-Packard, Palo Alto, CA, USA) was used. UV spectra were recorded between 200 and $450 \mathrm{~nm}$ and the UV trace was measured at $360 \mathrm{~nm}$. A Symmetry $\mathrm{C}_{18}$ analytical column $(250 \times 4.6 \mathrm{~mm}$ i.d.; particle size, $5 \mu \mathrm{m}$ ) fitted with a Novapack RP $\mathrm{C}_{18}$ guard column (Waters, Millford, MA) were used for the separation. The mobile phase consisted of $0.5 \%$ formic acid in deionized water (A) and $0.5 \%$ formic acid in acetonitrile:methanol (50:50, v/v) (B). The gradient program was as follows: $25 \%$ B to $40 \%$ B in $20 \mathrm{~min}, 40 \%$ $\mathrm{B}$ to $50 \% \mathrm{~B}$ in $5 \mathrm{~min}, 50 \%$ to $100 \% \mathrm{~B}$ in $5 \mathrm{~min}$ followed by $100 \% \mathrm{~B}$ in $5 \mathrm{~min}$ at a flow rate of $1 \mathrm{~mL} \mathrm{~min} \mathrm{~m}^{-1}$. There was a 10-min post-run going back to the starting conditions for reconditioning. The column oven temperature was kept at $40{ }^{\circ} \mathrm{C}$. The injection volume was $10 \mu \mathrm{L}$.

The classical shift reagents were prepared according to the literature. ${ }^{18}$ The reagents used in post-column derivatization system were all aqueous solutions, as follows: strong base, sodium hydroxide $\left(0.02 \mathrm{~mol} \mathrm{~L}^{-1}\right)$; aluminum chloride $\left(0.3 \mathrm{~mol} \mathrm{~L}^{-1}\right.$; with this reagent, the reaction coil was heated up to $\left.60{ }^{\circ} \mathrm{C}\right)$; sodium acetate $(0.5$ mol L $\left.{ }^{-1}\right)$. The solvent delivery system comprised two M6000 pumps, a M-720 gradient controller and a U6K injector (Waters). The photodiode array detector HP1040A (Hewlett-Packard) coupled with an HP-85 personal computer (Hewlett-Packard) was used for recording chromatogram and UV-Vis spectra. For post-column derivatization, an Eldex Model A-30-5-2 (Eldex Labs, Menlo Pak, CA, USA) pump and a reaction coil were employed. Shift reagents were added to the eluent at a flow rate of $0.2 \mathrm{~mL} \mathrm{~min}^{-1}$. 
LC/MS detection was performed directly after UVPAD measurements. Analyses were performed using a Finnigan MAT LCQ (San Jose, CA, USA) ion trap mass spectrometer (IT-MS) equipped with a Finnigan electrospray (ESI) interface, operated under the following conditions: capillary temperature $225^{\circ} \mathrm{C}$, capillary voltage $-57 \mathrm{~V}$, cone voltage $-35 \mathrm{~V}$, spray voltage $-2.8 \mathrm{kV}$ and gas nebuliser flow $\left(\mathrm{N}_{2}\right) 4 \mathrm{~L} \mathrm{~min}^{-1}$. Product ion mass spectra were recorded in the range of $m / z$ 150-1000. CID was performed applying 30\% of energy level. Energy levels on the Finnigan IT-MS are given in $\%$ and not in $\mathrm{eV}$ since the voltages applied vary according to the $m / z$ value of precursor ions. The MS/MS method was used in the negative ion mode and was based on scan-dependent type experiments: the most-abundant ion was automatically selected as precursor ion and fragmented up to the $\mathrm{MS}^{4}$ stage, each successive most-abundant fragment ion being selected again as precursor ion for next step. The instrument parameters were optimized using rutin prior to analysis of apple extracts.

\section{Results and Discussion}

\section{General aspects}

The elution conditions were established by testing several gradients of three different mobile phases: wateracetonitrile, water-methanol and water-(acetonitrile: methanol 50:50 v/v), to all of which $0.5 \%$ formic acid was added to avoid tailing of the chromatographic peaks. The latter proved to be the best mobile phase for separating the apple compounds and also proved suitable for electrospray ionization. The temperature for this analysis $\left(40{ }^{\circ} \mathrm{C}\right)$ was optimized considering both separation and resolution of chromatographic peaks.

This study focused on the flavonoids present in apple peel extracts, because of the lower concentration of these compounds in the extracts prepared with the whole fruit, which were unsuitable for a LC/MS analysis. The LC/ UV chromatograms (Figure 1) showed similar profiles for the extracts of the three apple varieties, with the exception of the flavonol-3-glycoside corresponding to compound $\mathbf{5}$, which was not detected in the Golden apple peel extract (the small peaks with retention time close to the compound 5 are not flavonoids, according to their UV spectra). A total of eight flavonols (Figure 2) were identified by the on-line combination of LC/UV/MS data, as will be discussed below. Based on the overall on-line data, the apple peel extracts were compared with commercially available standards under the same analytical conditions. The comparison of the retention times, UV and mass

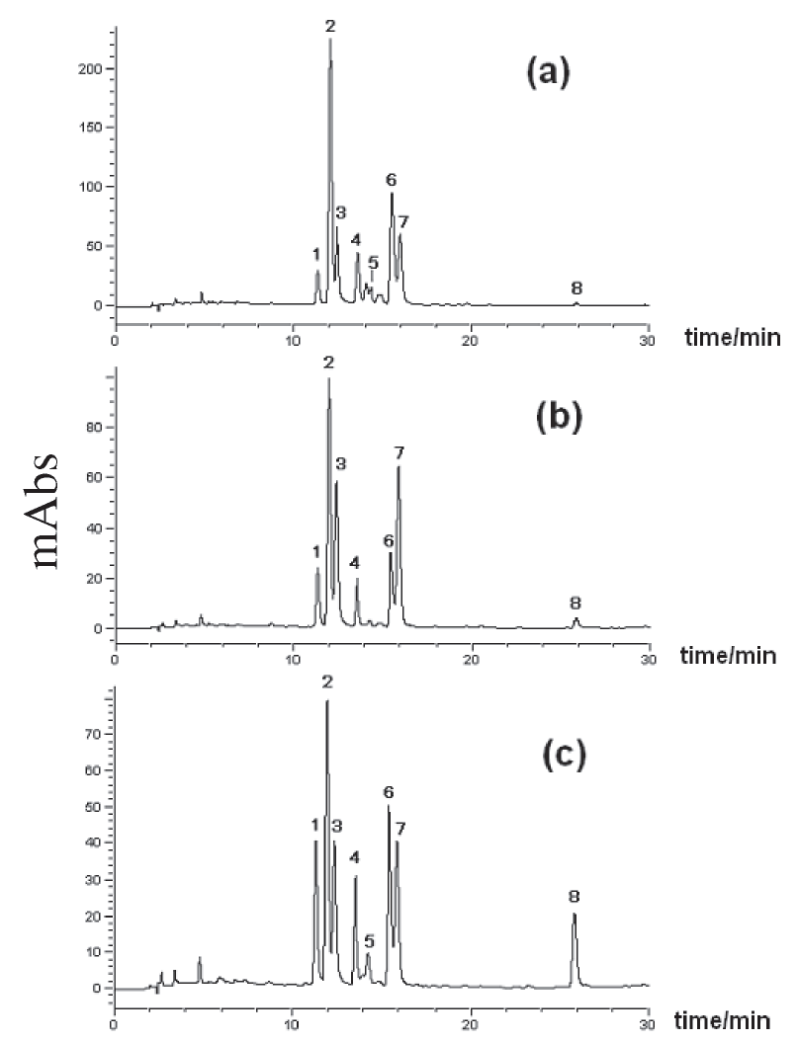

Figure 1. HPLC-UV/PAD chromatograms $(\lambda=360 \mathrm{~nm})$ of apple peel extracts. (a) Gala variety; (b) Golden variety and (c) Fuji variety. 1, rutin; 2, hyperoside; $\mathbf{3}$, isoquercetin; 4, quercetin-3-O-pentoside; 5, quercetin-3-Opentoside; 6, quercetin-3-O-pentoside; 7, quercetrin; 8, quercetin (chromatographic conditions described in Experimental, LC/UV/MS analysis).<smiles>[R2]c1c(-c2ccc(O)c(O)c2)oc2cc(O)cc(O)c2c1=O</smiles>

$\begin{array}{clll} & & \text { R } & \text { MM } \\ \mathbf{1} & \text { rutin } & \text { Glu-Rha } & 610 \\ \mathbf{2} & \text { hyperoside } & \text { Gal } & 464 \\ \mathbf{3} & \text { isoquercitrin } & \text { Glu } & 464 \\ \mathbf{4 - 6} & \text { quercetin-3-O-pentoside } & \text { pentose } & 434 \\ \mathbf{7} & \text { quercitrin } & \text { Rha } & 448 \\ \mathbf{8} & \text { quercetin } & \text { H } & 302\end{array}$

Figure 2. Structure of the flavonols identified in apple peel extracts.

spectra with those obtained from the standards provided unequivocal confirmation of the identification of rutin (1), hyperoside (2), isoquercitrin (3), quercitrin (7), and quercetin (8).

\section{LC/UV/MS analysis}

The on-line recording of UV spectra allowed for a rapid attribution of flavonol peaks, since these exhibit 
characteristic UV spectra (Table 1), with two maximum absorption $\left(\lambda_{\max }\right)$ bands at 240-280 nm (Band II) and 300$380 \mathrm{~nm}$ (Band I). Useful information was also obtained with the post-column addition of UV shift reagents according to a protocol already tested for flavonoids and xanthones. ${ }^{19,20}$ The shifted and original UV spectra were overlaid and compared for each peak, and the shifts were interpreted according to data reported in the literature. ${ }^{21}$ These analyses provided important complementary information on the structural features and oxygenation pattern for the on-line identification.

The UV spectra of peaks 1-8 (Table 1) indicated that all these molecules shared the same chromophore group and were probably flavonols ( $\mathrm{OH}$ group at position 3 ). However, compounds 1-7 showed $\lambda_{\text {max }}$ between 345-355 $\mathrm{nm}$ (Band I) and 250-260 nm (Band II), indicating the presence of a substituted 3-OH group, while compound $\mathbf{8}$ showed $\lambda_{\text {max }}$ at $365 \mathrm{~nm}$ (Band I) and $255 \mathrm{~nm}$ (Band II), suggesting a free 3-OH group.

Analyses of UV spectra in HPLC with the post-column addition of reagents are usually carried out in methanol. ${ }^{20}$ However, the conditions described herein involve HPLC analyses using an acidic acetonitrile-methanol-water system, which were employed on the shift reagents tested for the different standards of flavonols. The comparison of the on-line UV/PAD spectra with those obtained after the post-column addition of UV shift reagents (Figure 3) allowed for the determination of the substitution pattern on the aglycone, as follows: the addition of NaOAc showed a bathocromic shift in Band I (45-55 nm), revealing a hydroxyl group in position 4' of the cinnamoyl system, while a bathocromic shift was also observed in Band II (10-15 nm), confirming the presence of free 7-OH groups for all the compounds under investigation. UV spectra in the presence of $\mathrm{AlCl}_{3}$ exhibited bathocromic shifts in Band I (40-45 nm) as a result of complexes formed by $\mathrm{AlCl}_{3}$ with 3',4'-orthodihydroxyl groups in the B-ring, or with 4-keto and 5-hydroxyl groups. These data were observed for compound 1-8, indicating the substitution of two $\mathrm{OH}$ groups on ring $\mathrm{B}$, i.e., all the compounds studied here corresponded to quercetin derivatives.

On-line MS and $\mathrm{MS}^{\mathrm{n}}$ analyses were performed to ascertain the molar mass of the flavonols under investigation and the latter to obtain detailed structural information. In a previous study, single stage LC/MS using atmospheric pressure chemical ionization (APCI) in the positive ion mode was applied to the investigation of Basque cider apples of the Goikoetxea variety. ${ }^{10}$ However, in the present study, the negative ion mode showed better results in the ESI-MS analysis. ESI process results in limited fragmentation of the deprotonated molecule $[\mathrm{M}-\mathrm{H}]^{-}$, of the flavonol glycosides present in apple extracts $^{22,23}$ and therefore, $\mathrm{LC}_{\mathrm{MS}} \mathrm{M}^{\mathrm{n}}$ analyses by in-source CID were also carried out in this study.

The $[\mathrm{M}-\mathrm{H}]^{-}$ions were taken as precursors in the ESI$\mathrm{MS}^{2}$ analysis and yielded spectra corresponding to deprotonated aglicone species, $[\mathrm{A}-\mathrm{H}]^{-}$, formed due to the loss of sugar units, as observed for compounds 1-7 (Table 2). As shown for $\mathbf{1}$, the $[\mathrm{M}-\mathrm{H}]^{-}$ion in the ESI-MS spectrum was observed at $m / z$ 609, while ES-MS ${ }^{2}$ ion at $m / z 301$ was attributed to [M-H-146-162]-, with the loss of $308 \mathrm{u}$ corresponding to a rhamnose $(146 \mathrm{u})$ plus a glucose (162 u) moiety. For compounds 2 and 3, the [M-H] $]^{-}$ion

Table 2. On line ESI-IT-MS ${ }^{\mathrm{n}}$ data obtained in the analysis of apple extracts (negative ion mode)

\begin{tabular}{lcccc}
\hline Compound & $\mathrm{t}_{\mathrm{R}} / \min$ & $\mathrm{R}$ & {$[\mathrm{M}-\mathrm{H}]^{-}$} & $\frac{\text { Main fragments }}{$\cline { 3 - 4 }} \\
\cline { 4 - 5 } & & & $\mathrm{MS}^{2} \mathrm{MS}^{3} \mathrm{MS}^{4}$ \\
\hline $\mathbf{1}$ & 11.3 & Glu-Rha & 609 & 301179151 \\
$\mathbf{2}$ & 12.0 & Gal & 463 & 301179151 \\
$\mathbf{3}$ & 12.4 & Glu & 463 & 301179151 \\
$\mathbf{4}$ & 13.6 & pentose & 433 & 301179151 \\
$\mathbf{5}$ & 14.3 & pentose & 433 & 301271271 \\
$\mathbf{6}$ & 15.5 & pentose & 433 & 301179151 \\
$\mathbf{7}$ & 15.9 & Rha & 447 & 301179151 \\
$\mathbf{8}$ & 25.8 & H & 301 & nd nd nd \\
\hline
\end{tabular}

nd: not detected. Gal: galactose; Glu: glucose; Rha: rhamnose.

Table 1. On-line UV data of apple flavonols identified in this study

\begin{tabular}{|c|c|c|c|c|c|c|}
\hline \multirow[t]{3}{*}{ Compound } & \multicolumn{2}{|c|}{ UV spectra/nm } & \multicolumn{4}{|c|}{ Shifted UV spectra/nm } \\
\hline & \multirow[b]{2}{*}{ Band I } & \multirow[b]{2}{*}{ Band II } & \multicolumn{2}{|c|}{$+\mathrm{NaOAc}$} & \multicolumn{2}{|c|}{$+\left(\mathrm{AlCl}_{3}+\mathrm{NaOH}\right)$} \\
\hline & & & Band I & Band II & Band I & Band II \\
\hline 1 & 350 & 255 & $404,325 \mathrm{sh}$ & 266 & 390 & 265 \\
\hline 2 & 345 & 250 & $398,322 \mathrm{sh}$ & 262 & 390 & 260 \\
\hline 3 & 350 & 255 & $405,325 \mathrm{sh}$ & 270 & 390 & 265 \\
\hline 4 & 345 & 250 & $398,322 \mathrm{sh}$ & 260 & 390 & 255 \\
\hline 5 & 355 & 260 & $400,325 \mathrm{sh}$ & 270 & 400 & 270 \\
\hline 6 & 350 & 260 & $395,322 \mathrm{sh}$ & 275 & 390 & 265 \\
\hline 7 & 345 & 260 & $398,328 \mathrm{sh}$ & 270 & 385 & 266 \\
\hline 8 & 365 & 255 & $410,325 \mathrm{sh}$ & 265 & 410 & 260 \\
\hline
\end{tabular}

sh: shoulder. 
was observed at $\mathrm{m} / \mathrm{z}, 463$ and a similar ion obtained for compound 1 was observed in the ESI-MS; ${ }^{2}$ the ion of $\mathrm{m} / \mathrm{z}$ 301 was attributed to [M-H-162] $]^{-}$, corresponding to a loss of 162 u (hexose), i.e., galactose and glucose for compounds 2 and 3 , respectively. Compounds 4,5 , and 6 showed identical ESI-MS and ESI-MS ${ }^{2}$ data with $[\mathrm{M}-\mathrm{H}]^{-}$ ion at $\mathrm{m} / \mathrm{z} 433$ and a deprotonated aglycone ion [M-H$132]^{-}$at $\mathrm{m} / \mathrm{z} 301$, respectively; a loss of $132 \mathrm{u}$ corresponding to a pentose unit (possibly apiose, arabinose or xylose, which are the pentose units most frequently found in flavonol glycosides). For compound 7, the $[\mathrm{M}-\mathrm{H}]^{-}$ion was observed at $\mathrm{m} / \mathrm{z} 447$ and deprotonated aglycone ion [M-H-146] $]^{-}$at $m / z$ 301, as was observed for compounds 1-6, with a loss of $146 \mathrm{u}$ corresponding to a rhamnose. The spectra of compound $\mathbf{8}$ in the first stage showed the $[\mathrm{M}-\mathrm{H}]^{-}$ion at $\mathrm{m} / \mathrm{z}, 301$, which was attributed to the aglycone quercetin, while the ESI-MS ${ }^{2}$ spectrum showed the formation of $m / z 179\left(\mathrm{X}^{-}\right)$ion due to the fragmentation of rings A and B (Figure 3).

The ESI-MS ${ }^{3}$ and ESI-MS ${ }^{4}$ spectra of compounds 1-8 also provided specific information on the fragmentation of rings $\mathrm{A}$ and $\mathrm{B}$ (Figure 3), which resulted mainly in the formation of $m / z, 179\left(\mathrm{X}^{-}\right)$and $m / z 151\left(\mathrm{X}^{-}-\mathrm{CO}\right)$ ions. The elimination of neutral fragment $\mathrm{Y}\left(\mathrm{m} / \mathrm{z}, 122, \mathrm{MS}^{3}\right)$, followed by loss of $\mathrm{CO}\left(\mathrm{m} / \mathrm{z}, 28, \mathrm{MS}^{4}\right)$, was observed in compounds 1-7. For compound 8, the ESI-MS ${ }^{3}$ and ESI-MS ${ }^{4}$ spectra showed the formation of $m / z, 151\left(\mathrm{X}^{-} \mathrm{CO}\right)$ and $\mathrm{m} / z, 107$ $\left(\mathrm{X}^{-}-\mathrm{CO}-\mathrm{CO}_{2}\right)$ ions. Furthermore, $\mathrm{X}^{-}$showed losses of $29 \mathrm{u}$ of $\mathrm{CHO}^{-}$(neutral radical) and $30 \mathrm{u}$ of $\mathrm{CH}_{2} \mathrm{O}$ (neutral loss). These fragmentation results are in agreement with those obtained by Justesen ${ }^{24}$ who investigated flavonols present in herbal extracts by APCI-MS/MS in the negative ion mode (fragmentation pathways are shown in Figure 3; for ESI$\mathrm{MS}^{\mathrm{n}}$ spectra, see also Supplementary Information).

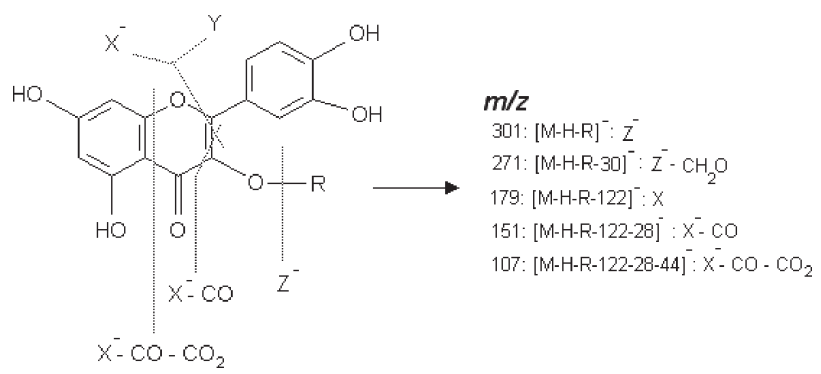

Figure 3. Structure and fragmentation pathways of flavonols by negative ion mode ESI-MS $^{\mathrm{n}}$.

\section{Conclusions}

The LC-hyphenated technique proved to be a rapid and efficient procedure for the characterization of targeted compounds, using analytical-scale conditions and small amounts of plant material, and also provided novel information on the chemical composition of the three Brazilian apple varieties (Gala, Golden, and Fuji).

The LC/UV/MS data presented herein showed similarities with the chemical composition of the apple samples studied here except for compound $\mathbf{5}$ (a quercetin3-O-pentoside), which was not found in the Golden cultivar. The presence of compounds 1-3 and $\mathbf{7}$ is in agreement with data reported for apples grown in North America and Europe..$^{25-29}$ On the other hand, aglycone quercetin $(\mathbf{8})$, which has been reported only once in the literature, ${ }^{10}$ was found in the three varieties cultivated in Brazil. Alonso-Salces et al. ${ }^{10}$ proposed that this aglycone has not been reported before, probably due to its low concentration. However, it would be also possible that $\mathbf{8}$ results from the hydrolysis of quercetin- $O$-glycosides during the sample preparation step, since apple fruit is rich in organic acids.

Furthermore, this study demonstrated, for the first time, the occurrence of three different quercetin-3- $O$-pentoside derivatives in apple peel extracts (Gala and Fuji), while previous reports reported the presence of only two quercetin-3-O-pentoside derivatives ${ }^{29}$ (as in the Golden variety). The differences between the data obtained in this study and that reported in the literature suggest variations in the composition of apple flavonols due to different varieties or growth conditions.

\section{Supplementary Information}

Supplementary data are available free of charge at http://jbcs.sbq.org.br, as PDF file.

\section{Acknowledgments}

The authors are grateful to Mr. Arioval Pioli (FischerFraiburgo Group, Fraiburgo, SC, Brazil) for furnishing apple samples. This work was supported by FAPESP (L.A.T. fellowship, 98/10271-0 and J.H.Y. research fellowships, 96/3107-3 and 02/00493-2), CNPq and CAPES.

\section{References}

1. Centro de Pesquisa Agropecuária de Clima Temperado, Ministério da Agricultura; Coleção Plantar: A Cultura da Maçã, EMPRAPA/ SPI: Brasília, Brasil, 1994, Vol. 19.

2. Dall'orto, F. A. C; Ojima, M.; Barbosa, W.; Castro, J. L.; Rigitano, O. In Melhoramento da Macieira em São Paulo; Boletim Técnico, Governo do Estado de São Paulo, Secretaria da Agricultura, Instituto de Ciências Agronômicas: Campinas, 1987. 
3. Dick, A. J.; Redden, P. R.; Demarco, A. C.; Lidster, P. D.; Grindley, T. B.; J. Agric. Food Chem. 1987, 35, 529.

4. Oleszek, W.; Lee, C. Y.; Jaworski, A. W.; Price, K. R.; J. Agric. Food Chem. 1988, 36, 430.

5. Escarpa, A.; González, M. C.; J. Chromatogr., A. 1998, 823, 331.

6. Awad, M. A.; de Jager, A.; van Westing, L. M.; Sci. Hortic. 2000, 83, 249.

7. Awad, M. A.; de Jager, A.; van der Plas, L. H. W.; van der Krol, A. R.; Sci. Hortic. 2001, 90, 69.

8. Schieber, A.; Keller, P.; Carle, R.; J. Chromatogr. A 2001, 910 , 265.

9. Schieber, A.; Keller, K.; Streker, P.; Klaiber, I.; Carle, R.; Phytochem. Anal. 2002, 13, 87.

10. Alonso-Salces, R. M.; Ndjoko, K.; Queiroz, E. F.; Ioset, J. R.; Hostettmann, K.; Berrueta, L. A.; Gallo, B.; Vicente, F.; J. Chromatogr. A 2004, 1046, 89.

11. Robards, K.; Antolovich, M.; Analyst 1997, 122, 11R.

12. Arabbi, P. R.; Genovese, M. I.; Lajolo, F.; J. Agric. Food Chem. 2004, 52, 1124.

13. Colombo, R.; Yariwake, J. H.; Queiroz, E. F.; Ndjoko, K.; Hostettmann, K.; J. Chromatogr. A 2005, 1082, 51.

14. Colombo, R.; Yariwake, J. H.; Queiroz, E. F.; Ndjoko, K.; Hostettmann, K.; Phytochem. Anal. 2006, 17, 337.

15. Wolfender, J.-L.; Hostettmann, K.; J. Chromatogr. A 2003, 1000, 437.

16. Crotti, A. E. M; Vessecchi, R.; Lopes, J. L. C.; Lopes, N. P. Quim. Nova 2006, 29, 287.

17. Hostettmann, K.; Wolfender, J.-L.; Terreaux, C.; Pharm. Biol. 2001, 39 Supl., 18.
18. Ducrey, B.; Wolfender, J.-L.; Marston, A.; Hosttetmann, K.; Phytochemistry 1995, 38, 129.

19. Hostettmann, K.; Domon, B.; Schaufelberger, D.; Hostettmann, M.; J. Chromatogr. 1984, 283, 137.

20. Wolfender, J.-L.; Hostettmann, K.; J. Chromatogr. 1993, 647, 191.

21. Markham, K. R.; Techniques of Flavonoid Identification, Academic Press Inc.: London, 1982.

22. Cuyckens, F.; Claeys, M.; J. Mass Spectrom. 2004, 39, 1.

23. de la Mora, J. F.; Van Berkel, G. J.; Enke, C. G.; Cole, R. B. Martinez-Sanchez, M.; Fenn, J. B.; J. Mass Spectrom. 2000, 35, 939.

24. Justesen, U.; J. Chromatogr., A 2000, 902, 369.

25. Hollman, P. C. H.; van Trijp, J. M. P.; Buysman, M. N. C. P.; Gaag, M. S. v.d.; Mengelers, M. J. B.; Vries, J. H. M.; Katan, M. B.; FEBS Lett. 1997, 418, 152.

26. Knekt, P.; Isotupa, S.; Rissanen, H.; Helliovaara, M.; Jarvinen, R.; Hakkinen, S.; Aromaa, A.; Reunanen, A.; Eur. J. Clin. Nutr. 2000, 54, 415.

27. Tsao, R.; Yang, R.; Young, J. C.; Zhu, H.; J. Agric. Food Chem. 2003, 51, 6347.

28. Tsao, R.; Yang, R.; J. Chromatogr. A 2003, 1018, 29.

29. Kahle, K.; Kraus, M.; Richling, E.; Mol. Nutr. Food Res. 2005, 49, 797.

Received: May 31, 2006

Web Release Date: November 24, 2006

FAPESP helped in meeting the publication costs of this article. 


\title{
On-line LC/UV/MS Analysis of Flavonols in the Three Apple Varieties Most Widely Cultivated in Brazil
}

\author{
Luciana A. Tiberti, ${ }^{a}$ Janete H. Yariwake, ${ }^{*, a}$ Karine Ndjoko ${ }^{b}$ and Kurt Hostettmann ${ }^{b}$ \\ ${ }^{a}$ Universidade de São Paulo, Instituto de Química de São Carlos, CP 780, 13560-970 São Carlos-SP, Brazil \\ ${ }^{b}$ Laboratoire de Pharmacognosie et Phytochimie, École de Pharmacie Genève-Lausanne, Université de Genève, Quai \\ Ernest Ansermet 30, 1211 Genève 4, Genève, Switzerland
}

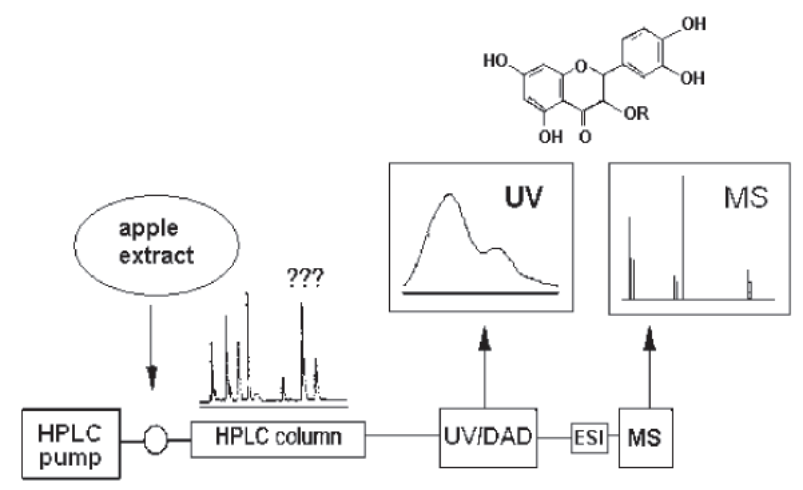

Figure S1. Schematic representation of the experimental setup used for LC/UV/MS analysis. 


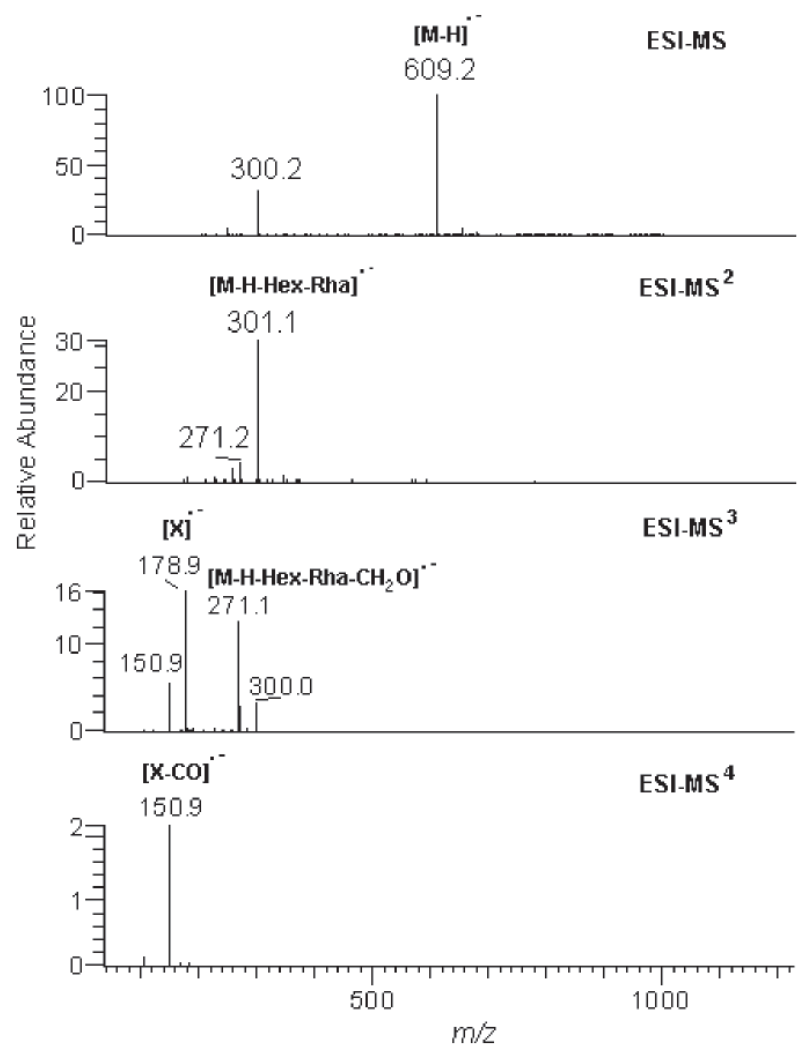

Figure S2. ESI-MS ${ }^{\mathrm{n}}$ spectra of 1 (rutin).
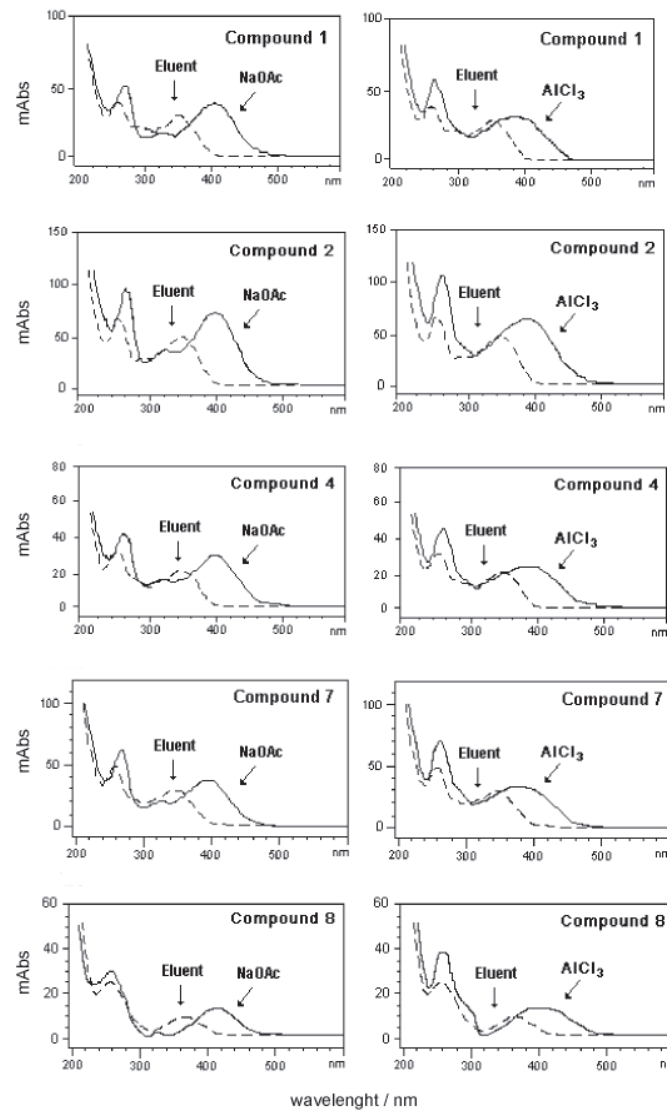

Figure S3. UV/PAD and shifted-UV spectra of compounds 1, 2, 4, 7, 8 recorded on-line.

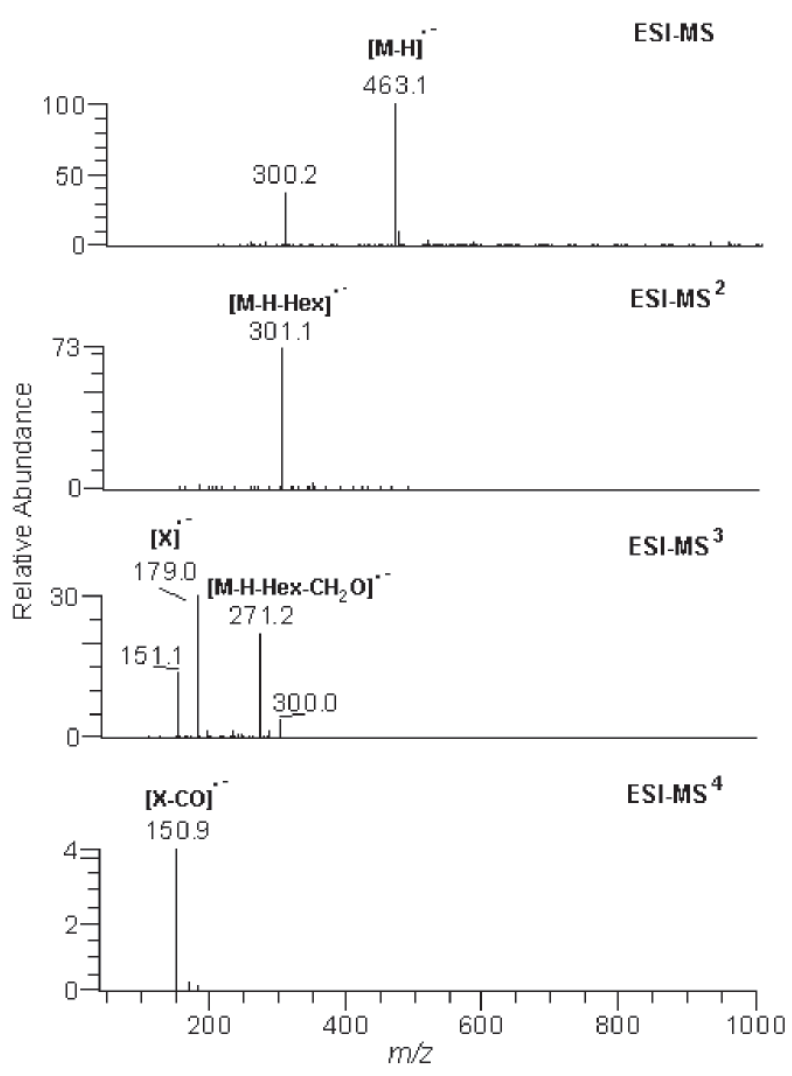

Figure S4. ESI-MS ${ }^{\mathrm{n}}$ spectra of $\mathbf{2}$ (hyperoside) and $\mathbf{3}$ (isoquercitrin).

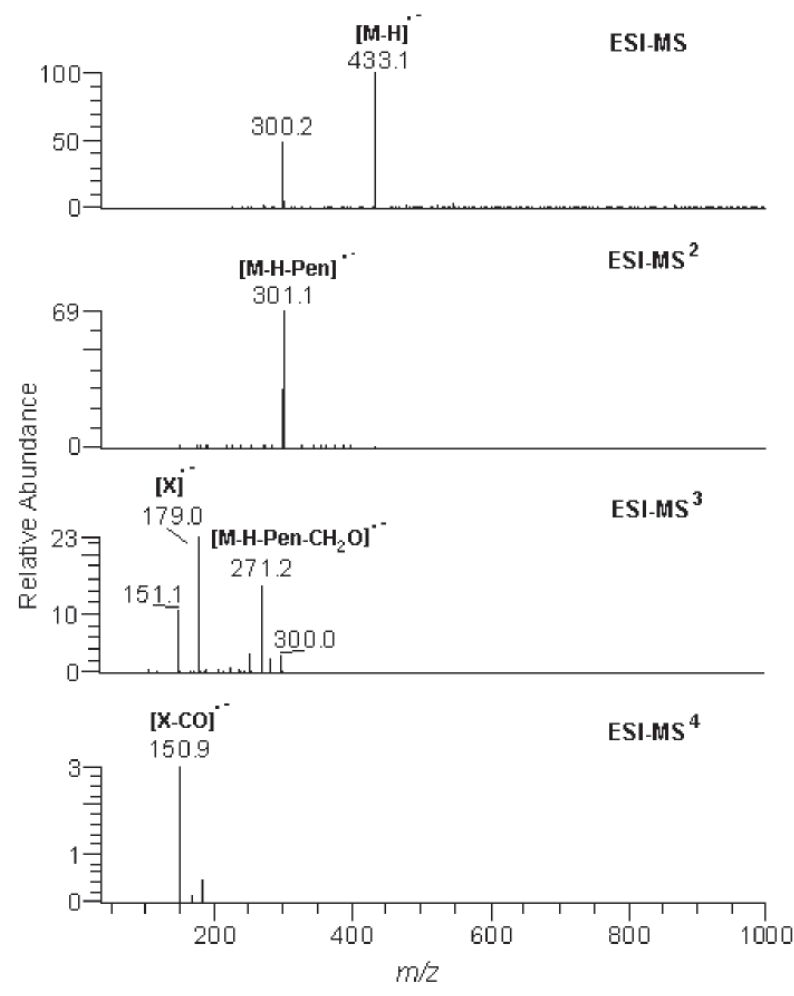

Figure S5. ESI-MS ${ }^{\mathrm{n}}$ spectra representative of the quercetin-3-Opentosides $(\mathbf{4}, \mathbf{5}$ and-6). 


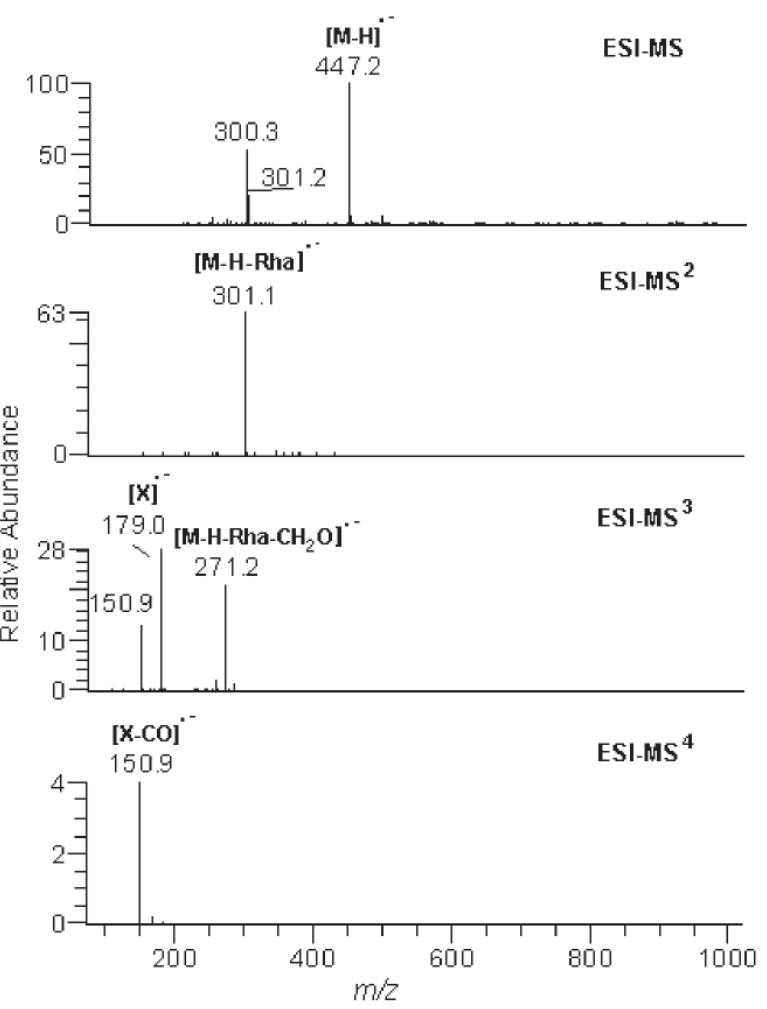

Figure S6. ESI-MS ${ }^{\mathrm{n}}$ spectra of 7 (quercitrin).
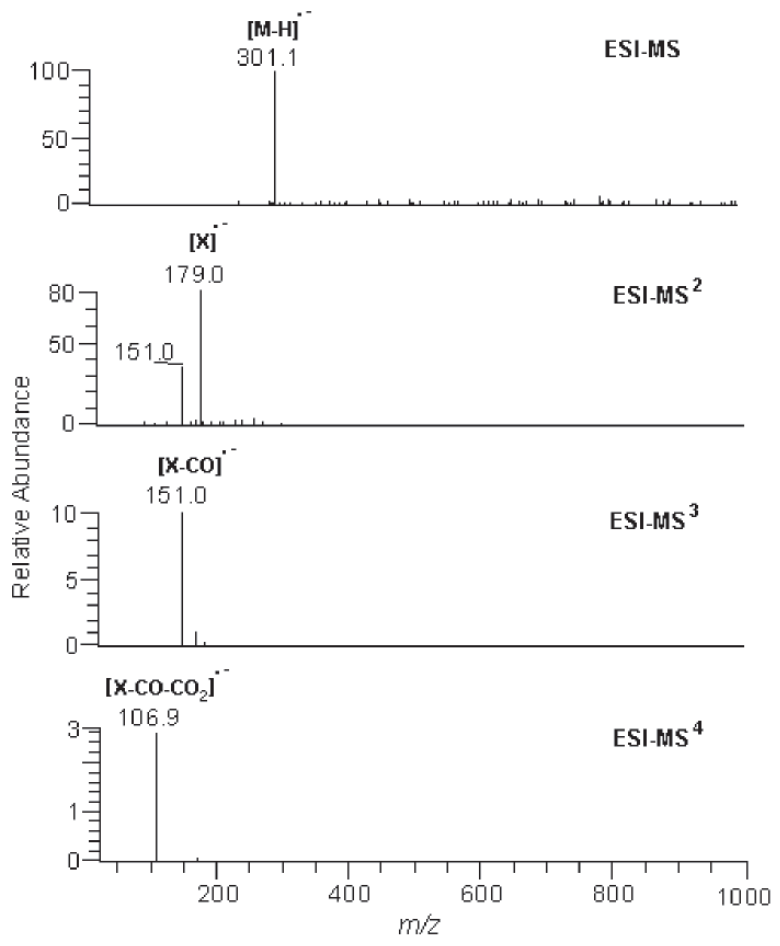

Figure S7. ESI-MS ${ }^{\mathrm{n}}$ spectra of $\mathbf{8}$ (quercetrin). 